\title{
CORRESPONDENCE
}

\section{Inaction speaks louder than words: tips for increasing black ACNP membership}

Neuropsychopharmacology (2021) 46:877; https://doi.org/10.1038/ s41386-020-00910-6

We read with interest the Commentary to by Henningfield et al. [1] on advancing equity, diversity, and inclusion in the American College of Neuropsychopharmacology (ACNP). "The ACNP has made noteworthy progress in its efforts to become more inclusive and to accelerate diversification in membership..." seems to be a key and desired takeaway for readers. Clearly, this issue is timely and important, and the authors should be commended for bringing the topic to the attention of the Journal's readership. Nonetheless, our enthusiasm was dampened because of a glaring omission of any substantive discussion regarding the embarrassingly low number of Black members within the College. Thus, we felt this issue warranted further discussion.

In 2019, Blacks comprised $1.3 \%$ of the ACNP membership, a number that has not appreciably grown since one of us $(\mathrm{CH})$ first attended the annual meeting in 1993. By contrast, the percentage of women members-predominantly white womenhas increased fourfold to $28 \%$. While the reasons for a practically non-existent Black membership aren't entirely clear, this shouldn't preclude scientists from grappling with possible explanations in an honest and unflinching manner. For example, the Commentary failed to address racial discrimination, which is a pervasive component of life in the US $[2,3]$. We were, therefore, surprised and disappointed by the omission of this pernicious factor as a possibility for the low number of Black members. It is important to note that racial discrimination need not result from malicious intent; it is merely actions or outcomes that result in disproportionately unjust or unfair treatment of persons from a specific racial group [4]. Perhaps ACNP's membership selection process, which is heavily reliant upon virtually all white individuals, should include formalized checks and balances that ensure a racially representative candidate pool. We recognize that a discussion about racial discrimination can be disconcerting for many US citizens, but in science we cannot simply ignore the possibility of its existence. Otherwise, we not only miss an opportunity to address the problem but also may send a message to prospective Black members that ACNP really isn't serious about weeding out racism in the College or society.

Another obvious and relevant unaddressed question is why Black scientists would even want to become ACNP members. The Commentary assumes that organizational statements purporting to value inclusion and diversity are meaningful to Black scientists. They are not; because they rarely, if ever, emphasize the importance of ameliorating health or societal concerns of Black people. The goals of increasing Black scientific involvement shouldn't simply be to increase the diversity numbers in an organization; they should also aim to address societal issues that unjustly, uniquely, or disproportionately impact Black people. For example, Hart [3] demonstrated how neuroscientists could help dispel myths about the inevitable toxic effects of drugs on the brain. These myths unduly harm Black people. The police-involved killings of Elijah McClain, Breonna Taylor, George Floyd, among others are cases in which ACNP, as an organization, and its individuals members could have attempted to remedy racist harms by, for example, devoting a special journal issue and dedicating conference sessions focusing solely on these issues. Of course, these pursuits should not be merely performative but must include Black experts and be outcome driven. Topics that could be addressed include cautioning against neuroimaging-data overinterpretations and advocating for drug policies that do not result in arrest or forced treatment for merely possessing recreational drugs. This would go a long way towards reducing the lopsidedly high Black incarceration rate. Further, it would reduce unnecessary police contact with Black people.

In closing, the summer of 2020 has shown with brutal clarity that Black life in the US is valued less than White life. If this observation does not move ACNP to act with a greater sense of urgency to increase its Black membership and contribute to mitigating societal problems underlying this grim reality, then its inaction will speak volumes.

\section{FUNDING AND DISCLOSURE}

The authors declared no conflicts related to the subject matter in this paper.

\section{AUTHOR CONTRIBUTIONS}

$\mathrm{CLH}$ wrote the initial draft and revised versions with intellectual input from JLC at each stage.

\section{ADDITIONAL INFORMATION}

Publisher's note Springer Nature remains neutral with regard to jurisdictional claims in published maps and institutional affiliations.

Carl L. Hart ${ }^{1,2}$ and Jean Lud Cadet iD ${ }^{3}$ ${ }^{1}$ Columbia University, Department of Psychology, New York, NY, USA; ${ }^{2}$ Division on Substance Use, New York State Psychiatric Institute, and Department of Psychiatry, New York, NY, USA and ${ }^{3}$ Molecular Neuropsychiatry Research Branch, NIH/NIDA Intramural Research

Program, Baltimore, MD, USA Correspondence: Carl L. Hart (clh42@columbia.edu)

\section{REFERENCES}

1. Henningfield J, Fields S, Anthony JC, Brown LS, Bolaños-Guzmán CA, Comer SD, et al. Advancing equity, diversity, and inclusion in the American College of Neuropsychopharmacology (ACNP): advances, challenges, and opportunities to accelerate progress. Neuropsychopharmacology. 2020;0:1-6. https://doi.org/ 10.1038/s41386-020-0784-y.

2. Hart CL. High Price: s neuroscientist's journey of self-discovery that challenges everything you know about drugs and society. New York, NY: Harper-Collins; 2013.

3. Hart CL. Exaggerating harmful drug effects on the brain is killing black people. Neuron 2020;107:215-8. https://doi.org/10.1016/j.neuron.2020.06.019.

4. Hart CL. Drug use for grown-ups: chasing liberty in the land of fear. New York, NY: Penguin; 2021 